\title{
Morphologic and Molecular Characterization of Isospora belli Oocysts from Patients in Thailand
}

\author{
Somchai Jongwutiwes,* Chaturong Putaporntip, Malee Charoenkorn, Takuya Iwasaki, and Takuro Endo \\ Department of Parasitology, Faculty of Medicine, Chulalongkorn University, Bangkok, Thailand; Department of Laboratory \\ Investigation, Institute of Tropical Medicine, Nagasaki University, Nagasaki, Japan; Division of Laboratory Medicine, National Iwate \\ Hospital, Iwate, Japan; Department of Parasitology, National Institute of Infectious Diseases, Tokyo, Japan
}

\begin{abstract}
To investigate the extent of genetic heterogeneity in the genus Isospora infecting patients in Thailand, a total of 38 fecal samples containing Isospora oocysts from human immunodeficiency virus/acquired immunodeficiency syndrome patients $(\mathrm{n}=30)$, corticosteroid-treated patients $(\mathrm{n}=3)$ and immunocompetent individuals $(\mathrm{n}=5)$ were recruited for analysis. Remarkable variation in the maximum width and length of oocysts both within and between isolates was observed. However, the average length-width ratio of oocysts was within the range for I. belli (> 1.2). Ex vivo sporogonic development of freshly passed oocysts in feces from three of these isolates was observed longitudinally, showing that $27 \%$ of these oocysts underwent complete sporulation. Interestingly, $95 \%$ of sporulated oocysts contained two sporocysts in an oocyst with four sporozoites in each sporocyst, and Caryospora-like oocysts, characterized by eight sporozoites enclosed by a single sporocyst, were also detected (5\%). The small subunit ribosomal RNA (rRNA), 5.8S rRNA, internal transcribed spacer 1 (ITS-1), and ITS-2 were highly conserved, indicating that there were no cryptic species or extensive strain variation.
\end{abstract}

\section{INTRODUCTION}

Isospora belli is a coccidian protozoa in phylum Apicomplexa that parasitizes epithelium of upper small intestine of humans and causes diarrheal disease. The entire life cycle of Isospora consists of asexual development and sexual reproduction that take place in the same host. Transmission of $I$. belli oocysts seems to be confined to the anthroponotic cycle because humans are the only known natural host. ${ }^{1}$ The oocysts of $I$. belli usually require less than one day to a few days after passage from human intestine to complete sporogonic development and become infective. ${ }^{2,3}$ Although both immunocompetent individuals and immunosuppressed patients are susceptible to infections, the prevalence of isosporiasis seems to occur more frequently in the latter. After the pandemic of human immunodeficiency virus-1 (HIV-1) infection, human isosporiasis has been more commonly identified as an opportunistic infection of the gastrointestinal tract of those who have low CD4+ lymphocyte counts (usually $<200$ cells $/ \mu \mathrm{l}$ ). ${ }^{4-6}$

Human isosporiasis seems to be cosmopolitan in distribution, especially in tropical and subtropical regions such as Haiti, Mexico, Brazil, El Salvador, Venezuela, and southeast Asia. ${ }^{1}$ However, the prevalence of this infection is occasionally underestimated because oocysts are usually excreted in small numbers or may not be found in spite of actual infection. ${ }^{7}$ Moreover, the transparent appearance of $I$. belli oocysts could be overlooked in direct fecal smears.

It is of note that infection with I. belli usually produces more aggressive and prolonged period of symptoms in patients with acquired immunodeficiency syndrome (AIDS) than in immunocompetent individuals. ${ }^{1,6}$ Among immunocompetent patients with isosporiasis, infants and young children seem to have more severe manifestations than in adults. Meanwhile, chronic diarrheal symptoms persisting for more than a decade caused by $I$. belli infections have been reported in adults without concurrent immunosuppression. ${ }^{1,8} \mathrm{Al}-$

* Address correspondence to Somchai Jongwutiwes, Department of Parasitology, Faculty of Medicine, Chulalongkorn University, Bangkok 10330, Thailand. E-mail: fmedsjw@md2.md.chula.ac.th though the gastrointestinal symptoms of patients with isosporiasis usually subside within a few days after initiation of treatment with combination of trimethoprim and sulfamethoxazole, relapses have been observed in approximately half of symptomatic cases. ${ }^{4,5}$ Thus, the spectrum of isosporiasis seems to be variable, partly depending on the host immune status whereas variation in virulence of parasite strains remains unknown.

A number of distinct species have been characterized for Cryptosporidium, another enteric coccidian protozoa that causes diarrheal illness in both humans and animals. Recent molecular epidemiologic studies have shown that cryptosporidia infecting humans belong to heterogenous species. ${ }^{9-11}$ Most of these species are responsible for zoonotic transmission, and anthroponotic cryptosporidiosis is caused by $C$. hominis. The knowledge of speciation in cryptosporidia is of considerable importance for disease control and prevention, especially for those with an immunosuppressive status, because no documented effective anti-cryptosporidial drug is available. $^{11}$

Despite the increased significance of enteric coccidiosis, comparatively little is known about species/strain variation in the genus Isospora infecting humans. To address this issue, we extracted the DNA from oocysts found in fecal samples of isosporiasis patients in Thailand and determined the sequences of the genes for small subunit ribosomal RNA (SSU rRNA), internal transcribed spacer (ITS), and 5.8S ribosomal RNA. We also analyzed morphologic features of oocysts of $I$. belli from patients with normal immune status and those with compromised immunity.

\section{MATERIALS AND METHODS}

Stool samples and background data. We obtained stool samples positive for I. belli oocysts from individuals at King Chulalongkorn Memorial Hospital in Bangkok, Thailand, as a cross-sectional study between January 2002 and December 2004. Isosporiasis was diagnosed by the presence of characteristic oocysts in one or more stool samples by direct wet smear method, formalin-ethylacetate sedimentation, or modi- 
fied kinyoun acid fast stain. Stool samples and clinical data of I. belli-infected cases were obtained after informed consent was obtained. These data included age, sex, presenting symptoms, history of illness, and relevant laboratory test results such as complete blood count and CD4+ lymphocyte count. Eosinophilia was determined based on a relative eosinophil count of more than 4 cells per 100 leukocytes. Diarrhea was defined as three or more unformed stools per day.

Aliquots of each I. belli-positive stool sample were preserved as described by adding approximately four volumes of absolute ethanol and storing at ambient temperature. ${ }^{12}$ Whenever possible, fresh stool samples were collected for observing sporulation of oocysts. The ethical aspects of this study were reviewed and approved by the Institutional Review Board of Faculty of Medicine, Chulalongkorn University.

Morphometry of oocysts. The dimension of each oocyst was determined by measuring maximum length and width with an Olympus (Center Valley, PA) BX51 light microscope at a magnification of 400 . At least 20 oocysts were measured for each sample.

Sporulation of oocysts. Fresh stool samples were directly diluted with an equal volume of sterile water. The stool suspension of each sample was applied onto more than 50 clean glass slides and covered with $22 \times 22 \mathrm{~mm}$ cover slips. The edges of the cover slips were tightly sealed, incubated at 25$30^{\circ} \mathrm{C}$, and kept in humidifier boxes to minimize evaporation of fluid from the samples. A total of 100 oocysts for each isolate were examined every 6 hours for 20 days by light microscopy using a magnification of $\times 400$.

DNA extraction. DNA of $I$. belli oocysts was extracted from either fresh stool samples or ethanol-preserved specimens by the method described for the extraction of Cryptosporidium oocysts, ${ }^{11}$ except that the QIAamp DNA Stool Mini Kit (Qiagen, Hilden, Germany) was used. Prior to DNA extraction of preserved samples, ethanol was removed by washing the samples with sterile water (by centrifugation 3 times at $1,600 \times g$ for 15 minutes without stopping) and the pellet was resuspended in $5 \mathrm{~mL}$ of water. The DNA purification procedure was essentially as described in the manufacturer's instruction manual. The purified DNA was dissolved in TE buffer (10 mM Tris-HCl, pH 8.0, and $1 \mathrm{mM}$ EDTA) and stored at $-20^{\circ} \mathrm{C}$ until used.

Polymerase chain reaction (PCR). The DNA fragment spanning the SSU rRNA, ITS-1, 5.8S rRNA and ITS-2 regions of $I$. belli was amplified by a nested PCR using primers whose sequences were derived from the $5^{\prime}$ portion of the SSU rRNA gene of $I$. belli isolate CI1 (GenBank accession no. U94787) and the $5^{\prime}$ portion of the 28S rRNA gene of I. felis (GenBank accession no. U85705). Sequences of the outer pair of primers were Iso-18SF0, 5'-CTGGTTGATCCTGCCAGTA-3' and Iso-28SR0, 5'-AAGGCTCAATCAAGAACCTCCG-3'. Sequences of the inner pair of primers were Iso-18SF1, 5'-GATCCTGCCAGTAGTCAT-3' and Iso-28SR1, 5'-TGAAGCTAATCCCTCTTCC-3'. We used the same thermal cycling profiles for both primary and secondary PCR: denaturation at $94^{\circ} \mathrm{C}$ for 40 seconds, annealing at $64^{\circ} \mathrm{C}$ for 40 seconds, extension at $74^{\circ} \mathrm{C}$ for 5 minutes for 35 cycles of amplification. DNA amplification was performed by using a GeneAmp 9700 PCR thermal cycler (Applied Biosystems, Foster City, CA). To minimize the error introduced in the sequences during PCR amplification, we used ExTaq
DNA polymerase (Takara, Shiga, Japan) that has efficient 5' $\rightarrow 3^{\prime}$ exonuclease activity to increase fidelity and shows no strand displacement. The size of PCR product was examined by electrophoresis in a $1 \%$ agarose gel and visualized with an ultraviolet transilluminator (Mupid Scope WD, Japan). The PCR product was purified by using the QIAquick PCR purification kit (Qiagen).

Subcloning. The GeneJET TM PCR Cloning Kit was used for ligating the purified PCR product to the plasmid vector pJET1/blunt (Fermentas, Burlington, Ontario, Canada). After incubation at $15^{\circ} \mathrm{C}$ for 6 hours, the reaction mixture was precipitated, redissolved in $10 \mu \mathrm{L}$ of double-distilled water, and transformed into Escherichia coli strain JM107 by electroporation using an E. coli pulser apparatus (Bio-Rad Laboratories, Hercules, CA). Recombinant DNA from positive clones was prepared by using the QIAGEN plasmid mini kit (Qiagen).

DNA sequencing. DNA sequences were determined directly from both PCR-purified templates and plasmid subclones. Sequencing analysis was performed in both directions for each template using the Big Dye Terminator version 3.1 Cycle Sequencing Kit on an ABI310 Genetic Analyzer (Applied Biosystems). Overlapping sequences were obtained by using sequencing primers (available upon request). Whenever one substitution occurred, the sequence was re-determined using PCR products from two independent amplifications from the same DNA template.

Data analysis. Sequences were aligned according to their primary and secondary structures by the CLUSTAL $\mathrm{X}$ and the MARNA programs, respectively. ${ }^{13,14}$ Phylogenetic construction was performed by the neighbor-joining method using the Kimura-2 parameter and 1,000 bootstrap iterations as implemented in the MEGA version 3.1 program. ${ }^{15}$ To analyze the evolutionary relationship, homologous sequences of other coccidian parasites available in the GenBank database were incorporated for comparison: I. belli (AF106935), I. ohioensis (AF029303), I. suis (U97523), I. orlovi (AY365026), I. felis (L76471), Toxoplasma gondii (M97703 and L49390), Cryptosporidium parvum (AF093490 and AF015773), Cyclospora cayetanensis (U40261 and AF301391), Neospora caninum (U16159 and L49389), Hammondia heydorni (AF317282), H. hammondi (AF096498), Eimeria tenella (U40264), and E. papillata (AY779501). New nucleotide sequence data obtained in this study have been deposited in the GenBank database under accession nos. DQ060658Q060683.

\section{RESULTS}

Patient profiles. Between January 2002 and December 2004, stool samples from 39,510 individuals were submitted to parasitology laboratory of King Chulalongkorn Memorial Hospital in Bangkok for detection of enteric parasites. Of these, 497 were from confirmed HIV/AIDS patients. Isosporiasis was identified in 38 patients by the presence of $I$. belli oocysts in their stool samples: 12 found by direct wet smear method (31.6\%), 37 by formalin-ethylacetate sedimentation $(97.4 \%)$ and 36 by modified kinyoun acid fast stain $(94.7 \%)$. Isosporiasis patients comprised 35 Thai persons from diverse regions of the country and 3 recent immigrants from Cambodia, Laos, and Pakistan.

Of all $I$. belli-infected patients, 30 were HIV positive, 3 
received prolonged corticosteroid therapy for systemic lupus erythematosus or idiopathic thrombocytopenic purpura, and 5 were immunocompetent individuals. More than half of isosporiasis patients were 30-39 years of age and the ratio of males to females 1.38:1. Laboratory tests showed relative eosinophilia ( $>4 \%$ ) in half of HIV-positive cases and all immunocompetent patients but none in the patients receiving prolonged corticosteroid treatment (Table 1). The absolute CD4+ lymphocyte counts in HIV-positive cases were 8-484 cells $/ \mu \mathrm{L}($ mean $\pm \mathrm{SD}=67.5 \pm 57.4$ cells $/ \mu \mathrm{L})$. Among HIVinfected cases, concurrent infections with one or more of the following pathogens occurred in 9 patients: herpes simplex virus, herpes zoster virus, Histoplasma capsulatum, Mycobacterium tuberculosis, Salmonella group B, and Strongyloides stercoralis.

All HIV-infected individuals developed watery diarrhea ranging from 1 week to 1 year (mean $\pm \mathrm{SD}=3.3 \pm 3.4$ months) prior to attending King Chulalongkorn Memorial Hospital. Two patients who received corticosteroids had chronic watery diarrhea and one patient who received this treatment had no symptoms. The clinical profiles of isosporiasis in immunocompetent patients were asymptomatic in two patients, chronic watery diarrhea in two patients, and dyspepsia without diarrhea in one patient. Diarrhea and associated gastrointestinal symptoms resolved within a few days after initiation of treatment with a combination of trimethoprim and sulfamethoxazole. During two months of follow-up, relapse occurred once each in two HIV-infected patients and one immunocompetent patient that was controlled by longterm prophylaxis with trimethoprim and sulfamethoxazole.

Oocyst morphometry. The oocyst dimension of each isolate varied from 17 to $37 \mu \mathrm{m}$ (mean $\pm \mathrm{SD}=28.3 \pm 3.0 \mu \mathrm{m})$ in length and from 8 to $21 \mu \mathrm{m}$ (mean $\pm \mathrm{SD}=13.5 \pm 1.9 \mu \mathrm{m})$ in width, and the mean \pm SD shape index (length divided by width) was $2.1 \pm 0.31$ (range $=3-3.3$ ). Although oocysts showed shape and size variations both within and between isolates, the shape indices of all oocysts observed in this study were consistent with that of $I$. belli, being more than 1.2, which was distinct from those for other species of Isospora infecting nonhuman mammals $(<1.2){ }^{1}$

Sporulation of oocysts. We were able to follow oocyst maturation using fresh watery stool samples from two HIVinfected patients and one immunocompetent subject who had not yet taken anti-coccidial drugs. A total of 100 oocysts were observed for each isolate. The average number of oocysts of these samples that underwent complete formation of sporozoites was 27 (range $=20-33$ ). The duration for an oocyst to transform into two sporocysts, each of which contained four sporozoites, ranged from 24 hours to 10 days (mean \pm SD $=$ $3.9 \pm 3.4$ days $)(n=66)$. Interestingly, Caryospora-like oocysts, characterized by oocysts containing one sporocyst that enclosed eight sporozoites, appeared on day 5-14 after incubation. Although this type of oocyst could be found in all three isolates, they occurred at a low frequency (approximately 5\%) (Figure 1). The dimensions of Caryospora-like oocysts did not differ significantly from those having bisporocysts.

SSU rRNA, ITS-1, 5.8S rRNA and ITS-2 sequences. The DNA fragment generated from the secondary PCR encompassing the SSU rRNA, ITS-1, 5.8S rRNA, and ITS-2 genes contained 3,049 basepairs. All isolates yielded single PCR fragments of identical size. Of these, we determined the se-

TABLE 1

Clinical profiles of isosporiasis and morphometry of Isospora belli oocysts*

\begin{tabular}{|c|c|c|c|c|c|c|c|}
\hline \multirow[b]{2}{*}{ Patient profiles } & \multirow[b]{2}{*}{$\mathrm{n}$} & \multirow[b]{2}{*}{$\begin{array}{l}\text { Age (years) } \\
\text { mean } \pm \text { SD } \\
\text { (range) }\end{array}$} & \multirow[b]{2}{*}{$\begin{array}{c}\mathrm{CD} 4+\text { cells } / \mu \mathrm{L} \\
\text { mean } \pm \mathrm{SD} \\
(\text { range })\end{array}$} & \multirow[b]{2}{*}{$\begin{array}{l}\text { Eosinophils (\%) } \\
\text { mean } \pm \text { SD } \\
\text { (range) }\end{array}$} & \multicolumn{3}{|c|}{ Oocyst dimensions $\dagger$} \\
\hline & & & & & $\begin{array}{l}\text { Length }(\mu \mathrm{m}) \\
\text { mean } \pm \text { SD } \\
\text { (range) }\end{array}$ & $\begin{array}{l}\text { Width }(\mu \mathrm{m}) \\
\text { mean } \pm \text { SD } \\
\text { (range) }\end{array}$ & $\begin{array}{l}\text { Shape index } \\
\text { mean } \pm \text { SD } \\
\text { (range) }\end{array}$ \\
\hline \multicolumn{8}{|c|}{ HIV infection (18 males, 12 females) } \\
\hline \multicolumn{8}{|l|}{ Diarrhea } \\
\hline$\leq 3$ weeks & 5 & $\begin{array}{c}35.6 \pm 11.0 \\
(23-52)\end{array}$ & $\begin{array}{c}104.3 \pm 25.7 \\
(89-134)\end{array}$ & $\begin{array}{c}5.4 \pm 3.6 \\
(0.4-9.1)\end{array}$ & $\begin{array}{c}27.2 \pm 2.6 \\
(18-33)\end{array}$ & $\begin{array}{c}12.8 \pm 1.8 \\
(8-19)\end{array}$ & $\begin{array}{l}2.2 \pm 0.3 \\
(1.3-3.0)\end{array}$ \\
\hline$>3$ weeks $-<1$ year & 22 & $\begin{array}{c}36.7 \pm 6.9 \\
(25-50)\end{array}$ & $\begin{array}{c}60.4 \pm 52.9 \\
(8-480)\end{array}$ & $\begin{array}{c}4.5 \pm 3.3 \\
(0.1-14.0)\end{array}$ & $\begin{array}{c}28.4 \pm 2.9 \\
(17-35)\end{array}$ & $\begin{array}{c}13.7 \pm 1.9 \\
(8-21)\end{array}$ & $\begin{array}{l}2.1 \pm 0.3 \\
(1.3-3.3)\end{array}$ \\
\hline$\geq 1$ year & 3 & $\begin{array}{c}27.7 \pm 8.3 \\
(21-37)\end{array}$ & $\begin{array}{l}80.3 \pm 53.6 \\
(25-484)\end{array}$ & $\begin{array}{l}3.5 \pm 1.8 \\
(2.0-5.5)\end{array}$ & $\begin{array}{c}28.4 \pm 3.8 \\
(18-34)\end{array}$ & $\begin{array}{c}13.8 \pm 2.2 \\
(10-19)\end{array}$ & $\begin{array}{l}2.1 \pm 0.4 \\
(1.4-3.0)\end{array}$ \\
\hline \multicolumn{8}{|c|}{ Corticosteroid treatment ( 1 male, 2 females $)$} \\
\hline No symptom & 1 & 37 & ND & 0.8 & $\begin{array}{c}33.7 \pm 2.0 \\
(30-37)\end{array}$ & $\begin{array}{c}14.0 \pm 1.6 \\
(12-18)\end{array}$ & $\begin{array}{l}2.4 \pm 0.2 \\
(1.9-2.7)\end{array}$ \\
\hline \multicolumn{8}{|l|}{ Diarrhea } \\
\hline$\leq 3$ weeks & 1 & 51 & ND & 0 & $\begin{array}{c}28.3 \pm 2.6 \\
(23-32)\end{array}$ & $\begin{array}{c}12.8 \pm 1.2 \\
(10-15)\end{array}$ & $\begin{array}{l}2.2 \pm 0.3 \\
(1.8-3.1)\end{array}$ \\
\hline$>3$ weeks & 1 & 23 & ND & 1.0 & $\begin{array}{c}27.4 \pm 2.1 \\
(23-30)\end{array}$ & $\begin{array}{c}13.4 \pm 1.3 \\
(11-16)\end{array}$ & $\begin{array}{l}2.1 \pm 0.3 \\
(1.4-2.6)\end{array}$ \\
\hline \multicolumn{8}{|c|}{ Immunocompetence ( 3 males, 2 females) } \\
\hline No symptoms & 1 & 37 & ND & 12.0 & $\begin{array}{c}28.0 \pm 1.9 \\
(25-31)\end{array}$ & $\begin{array}{c}14.0 \pm 1.9 \\
(11-17)\end{array}$ & $\begin{array}{l}2.0 \pm 0.3 \\
(1.5-2.5)\end{array}$ \\
\hline Dyspepsia & 1 & 31 & ND & 11.1 & $\begin{array}{c}30.3 \pm 2.6 \\
(25-35)\end{array}$ & $\begin{array}{c}13.7 \pm 1.2 \\
(12-16)\end{array}$ & $\begin{array}{l}2.2 \pm 0.3 \\
(1.6-2.5)\end{array}$ \\
\hline \multicolumn{8}{|l|}{ Diarrhea } \\
\hline$<1$ year & 2 & $\begin{array}{c}30.5 \pm 2.1 \\
(29-32)\end{array}$ & ND & $\begin{array}{c}8.5 \pm 0.7 \\
(8.0-9.0)\end{array}$ & $\begin{array}{c}27.0 \pm 2.4 \\
(20-32)\end{array}$ & $\begin{array}{c}12.6 \pm 2.2 \\
(9-18)\end{array}$ & $\begin{array}{l}2.2 \pm 0.4 \\
(1.5-3.1)\end{array}$ \\
\hline$\geq 1$ year & 1 & 57 & 730 & 16.0 & $\begin{array}{c}28.4 \pm 1.4 \\
(26-30)\end{array}$ & $\begin{array}{c}15.6 \pm 1.7 \\
(12-17)\end{array}$ & $\begin{array}{l}1.8 \pm 0.2 \\
(1.6-2.3)\end{array}$ \\
\hline
\end{tabular}

$* \mathrm{HIV}=$ human immunodeficiency virus; $\mathrm{ND}=$ not determined

$\dagger$ Measurement under $400 \times$ magnification from 20 oocysts from each isolate. 


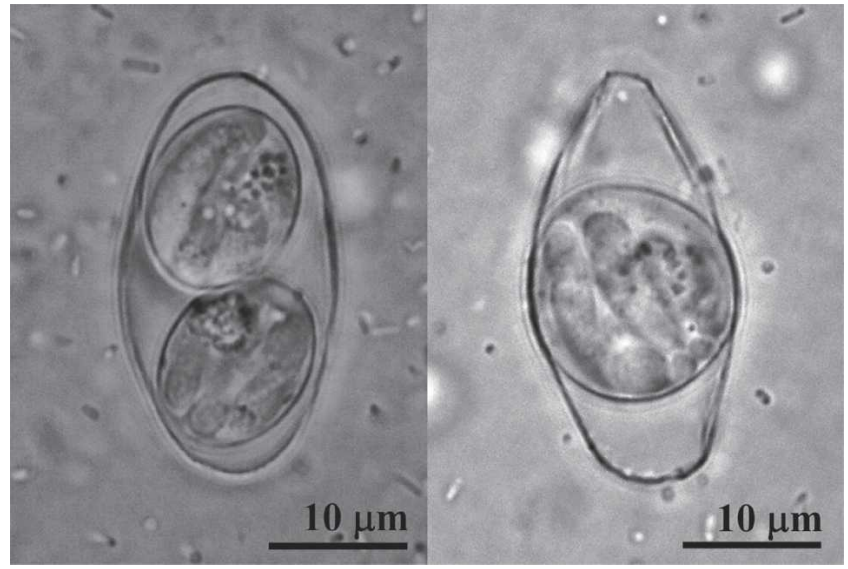

FIGURE 1. Oocysts of Isospora belli showing a sporulated oocyst containing two sporocysts, each of which contains 4 sporozoites (left) and a Caryospora-like oocyst containing sporozoites enclosed in a single sporocyst (right).

quences of 26 isolates from HIV-infected patients $(\mathrm{n}=23)$, symptomatic immunocompetent individuals $(n=2)$, and an asymptomatic immunocompetent subject. We did not find any remarkable preponderance toward purine or pyrimidine composition in the region analyzed ( $\% \mathrm{GC}=47.1 \%)$. Sequences of the SSU rRNA gene, spanning 1,778 basepairs, of 25 isolates examined were identical with those of strains CI1 and CJLPHD2 (GenBank accession nos. U94787 and AF441289), but differed from the isolate reported by Franzen and others (GenBank accession nos. AF106935) at A679T and A682C. ${ }^{16}$ Three additional nucleotide substitutions occurred at T583C, C638A, and G1240T in the isolate from an immunocompetent patient who had multiple relapses.

The 5.8S rRNA, ITS-1, and ITS-2 regions contained 598, 158 and 404 basepairs, respectively. Both the 5.8S rRNA and ITS-2 sequences of $I$. belli showed perfect sequence identity among all isolates examined. Likewise, sequences of the ITS-1 were highly conserved, except for one nucleotide substitution at position 528 with an $A$ to $G$ change (position according to the ITS-1 region). However, there was no association between this nucleotide substitution and clinical severity of the infected individuals. Comparison of the $5.8 \mathrm{~S}$
rRNA of $I$. belli with those of other coccidian parasites showed a high similarity of sequences (Figure 2). Conversely, the ITS-1 and ITS-2 regions showed extensive sequence diversity.

Phylogenetic analysis. The neighbor-joining tree derived from the SSU rRNA sequences confirmed that all isolates of I. belli in this study were clustered, which is consistent with a single species (Figure 3). Further analysis using the available complete sequences of the SSU rRNA gene of the genera Toxoplasma, Cryptosporidium, Cyclospora, Isospora, Neospora, Eimeria, and Hammondia, which were aligned according to their secondary structure, showed that I. belli was more related to Toxoplasma, Neospora, and Hammondia than to Cyclospora, Eimeria, and Cryptosporidium. An identical topology of a phylogenetic tree to that inferred from the SSU rRNA sequences was reaffirmed when the ITS- 2 sequences were used for comparison (Figure 4).

\section{DISCUSSION}

We searched for isosporiasis in a large number of patients who submitted their stool samples to King Chulalongkorn Memorial Hospital over a three-year period. The overall prevalence of $I$. belli-positive samples was approximately $0.1 \%$ on the basis of total samples examined. The prevalence of isosporiasis among HIV/AIDS patients in this study was $6.0 \%$ and decreased to $0.02 \%$ in non-HIV-infected cases. However, similar cross-sectional studies in Germany, Haiti, and Venezuela showed a higher prevalence, ranging from 14 to $48 \% .^{4,6,17}$ The low prevalence of isosporiasis in this study suggested that $I$. belli might not commonly circulate in the Thai population, resulting in a low prevalence of isosporiasis in HIV/AIDS patients in this country. Nevertheless, most isosporiasis patients in Thailand showed immunosuppression, comprising $86.8 \%$ of all positive cases.

Despite rapid improvement of symptoms after treatment with oral trimethoprim and sulfamethoxazole, recurrent isosporiasis occurred in three HIV/AIDS patients (approximately $8 \%$ ) within two months after initiation of treatment. Importantly, approximately half of Haitian patients who received the same or similar treatment had relapses. ${ }^{5}$ The duration and frequency of follow-up after treatment may have contributed

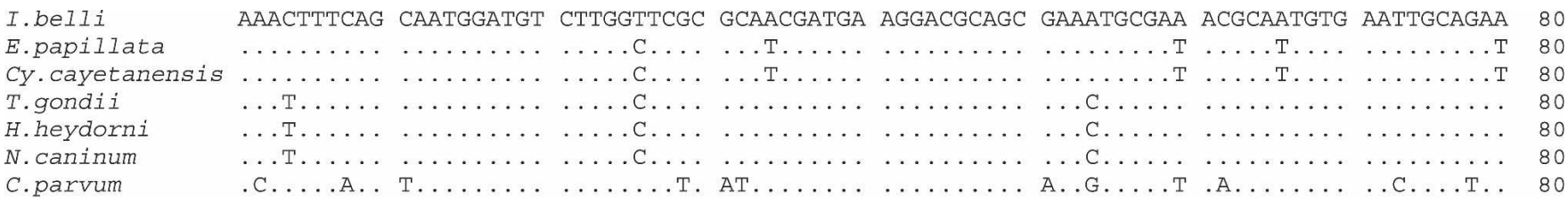

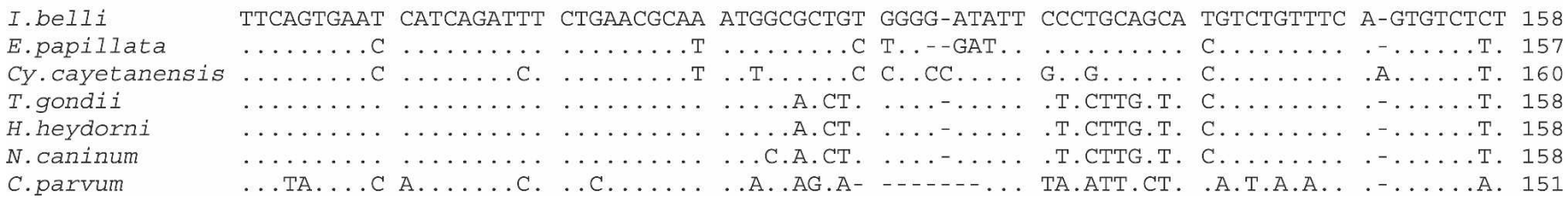

FIGURE 2. Alignment of the 5.8S ribosomal RNA sequences of Isopora belli with those of other coccidian protozoa. Dots and dashes represent identical residues and deletions, respectively. E. = Eimeria Cy. = Cyclospora T. $=$ Toxoplasma; H. = Hammondia . N. = Neospora; . = Cryptosporidium. 


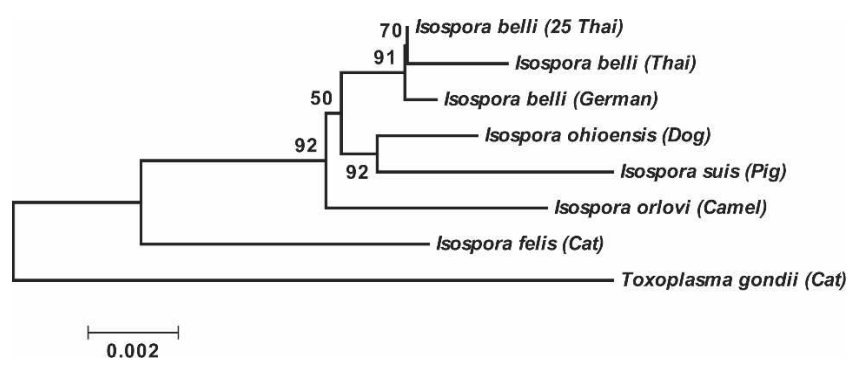

FIGURE 3. Phylogenetic relationships among isolates of Isospora belli in this study (DQ060658-83) and those reported by others (U94787 and AF106935) in relation to other nonhuman species of Isospora as inferred from small subunit ribosomal RNA sequences and the neighbor-joining method. Toxoplasma gondii was used as the outgroup. Bootstrap percentages more than $50 \%$ based on 1,000 iterations are shown on the branches. Host origins are shown in parentheses.

to the difference in observed relapsing episodes from each study. However, continuing anti-coccidial prophylaxis will be warranted in certain isosporiasis cases.

The life cycle of $I$. belli depends solely on monoxenous development in a human host without known natural animal reservoirs or paratenic hosts. Both schizogonic and sporogonic development take place intracellularly in epithelium of the small intestine. However, the stages of oocysts that are newly passed in feces contain mostly one sporont, but oocysts with two sporoblasts are occasionally encountered. To observe oocyst development ex vivo, we used fresh stool samples without preservatives, such as potassium dichromate, to envisage the fate of oocyst development when excreted into the environment. The duration for complete sporulation of $I$. belli described herein is rather variable. Although we used different experimental conditions from other studies, the earliest appearance of fully sporulated oocyst is similar, i.e., within 24 hours after passage from the host. ${ }^{2,3}$

It is well recognized that mature oocysts of $I$. belli produce two sporocysts, each with four sporozoites. Interestingly, a

\section{A}

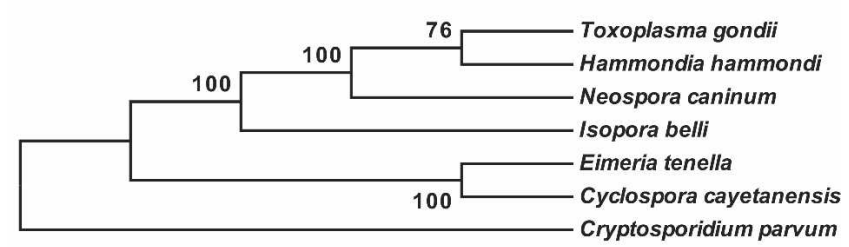

B

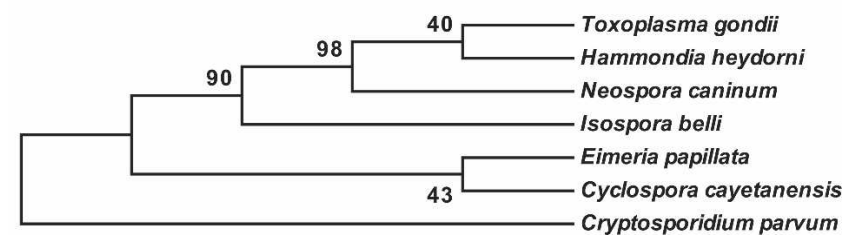

FIgURE 4. Topology of neighbor-joining trees derived from the small subunit ribosomal RNA (A) and the internal transcribed spacer 2 region (B) of Isospora belli and other coccidian protozoa using the Kimura-2 parameter. Bootstrap values based on 1,000 iterations are indicated on the branches. small percentage of approximately less than $2 \%$ of oocysts that underwent sporogonic development contained eight sporozoites in one sporocyst, which is known as Caryosporalike, has been reported in Isospora, such as I. canis, I. suis, and I. rivolta, that infect other mammals. ${ }^{18-20}$ The presence of Caryospora-like oocysts of I. belli was first described in 1968 by Zaman, who studied sporogonic development of $I$. belli in patients from Singapore. ${ }^{2}$ However, no additional studies have confirmed the presence of this stage. In this study, we demonstrated the presence of Caryospora-like oocysts in all three isolates examined after an extended period of incubation. Taken together, this stage could be an alternative ex vivo development stage of $I$. belli. Factors such as temperature, moisture, level of oxygen, and other unknown conditions could influence the capability and duration required for complete sporulation of this type of oocysts. ${ }^{1}$ For instance, the formation of Caryospora-like oocysts of the cat isosporan protozoa I. rivolta could be induced by brief heating of oocysts to $50^{\circ} \mathrm{C}$ before incubation. These oocysts remained viable and infectious to cats. ${ }^{21}$ Although we did not determine the effect of heat induction on the generation of Caryosporalike oocysts in I. belli, spontaneous development of this stage occurred during a range of five days to two weeks at ambient temperature $\left(25-30^{\circ} \mathrm{C}\right)$. If the viability period of $I$. belli in the environment after complete sporulation was limited, unsynchronized sporulation could extend the period of transmission of this important enteric coccidian protozoa.

Eukaryotic organisms possess the nuclear rRNA genes organized in clusters containing SSU rRNA, of which the 5.8S and $28 \mathrm{~S}$ subunits are separated by the two ribosomal RNA spacers ITS1 and ITS2. A remarkable feature of these ITS sequences is their high divergence between species, which makes them a suitable marker for speciation and phylogenetic studies. Our analysis of the SSU rRNA, ITS-1, 5.8S rRNA, and ITS-2 regions showed sequence conservation among isolates, except a minimal sequence variation in SSU rDNA and ITS-1. Therefore, cryptic species of Isospora infecting patients in this study were unlikely.

Phylogenetic relationships inferred from the SSU rRNA gene showed that Isospora is more closely related to the genera Neospora and Toxoplasma than to the genera Eimeria and Cyclospora, which is consistent with analysis by Franzen and others. ${ }^{16}$ Likewise, the phylogenetic tree derived from the informative sites of ITS-2 based on secondary structure alignment yielded results similar to those obtained from the SSU rRNA sequence, which supports the value of ITS-2 data for tracing evolutionary relationship of coccidian protozoa as those used in analysis of other organisms. ${ }^{22-24}$

In conclusion, unlike Cryptosporidium infecting humans that comprises both zoonotic and anthroponotic species, our study, on the basis of morphometric and molecular evidence, showed that human isosporiasis is caused by one species of $I$. belli. Although isosporiasis is more common among immunocompromised patients than immunocompetent hosts, it seems likely that severity of infections does not simply depend on the immune status of infected individuals because some immunocompetent patients exhibit chronic debilitating illness with multiple recurrent prolonged diarrheal episodes. ${ }^{1,8}$ Whether strain difference in I. belli could contribute to disease severity will require further investigation. In this regard, analysis of yet unknown polymorphic genetic markers in $I$. belli would be essential. 
Received December 29, 2006. Accepted for publication March 12, 2007.

Acknowledgments: We are grateful to all patients who participated in this study, and to Professors Hiroji Kanbara and Haruo Watanabe for valuable support.

Financial support: This study was supported by the Ministry of Labor and Welfare of Japan through The National Institute of Infectious Diseases (Tokyo); the Ratchadapiseksompotch Fund from the Faculty of Medicine, Chulalongkorn University (grant no. RA227/48); funds for devoted scholar from the Ananthamahidol Foundation to Somchai Jongwutiwes, and funds from the Faculty of Medicine, Chulalongkorn University to Somchai Jongwutiwes and Chaturong Putaporntip.

Authors' addresses: Somchai Jongwutiwes, Chaturong Putaporntip, and Malee Charoenkorn, Department of Parasitology, Faculty of Medicine, Chulalongkorn University, Rama 4 Road, Pathumwan, Bangkok 10330, Thailand. Takuya Iwasaki, Department of Laboratory Investigation, Institute of Tropical Medicine, Nagasaki University, 1-12-4 Sakamoto, Nagasaki 8528523, Japan; and Division of Laboratory Medicine, National Iwate Hospital, Iwate 0210056, Japan.Takuro Endo, Department of Parasitology, National Institute of Infectious Diseases, Toyama 1-23-1, Shinjuku-ku, Tokyo 162-8640, Japan.

Reprint requests: Somchai Jongwutiwes, Department of Parasitology, Faculty of Medicine, Chulalongkorn University, Bangkok 10330, Thailand, Telephone: 66-2-256-4000 extension 3685, Fax 66-2-2524963, E-mail: fmedsjw@md2.md.chula.ac.th.

\section{REFERENCES}

1. Lindsay DS, Dubey JP, Blagburn BL, 1997. Biology of Isospora spp. from humans, nonhuman primates, and domestic animals. Clin Microbiol Rev 10: 19-34.

2. Zaman V, 1968. Observations on human Isospora. Trans $R$ Soc Trop Med Hyg 62: 556-557.

3. Morakote N, Muangyimpong Y, Somboon P, Khamboonruang C, 1987. Acute human isosporiasis in Thailand: a case report. Southeast Asian J Trop Med Public Health 18: 107-111.

4. DeHovitz JA, Pape JW, Boncy M, Johnson WD, 1986. Clinical manifestations and therapy of Isospora belli infection in patients with the acquired immunodeficiency syndrome. $N$ Engl J Med 315: 87-90.

5. Pape JW, Verdier RI, Johnson WD Jr, 1989. Treatment and prophylaxis of Isospora belli infection in patients with the acquired immunodeficiency syndrome. N Engl J Med 320: 10441047.

6. Certad G, Arenas-Pinto A, Pocaterra L, Ferrara G, Castro J, Bello A, Nunez L, 2003. Isosporiasis in Venezuelan adults infected with human immunodeficiency virus: clinical characterization. Am J Trop Med Hyg 69: 217-222.

7. Brandborg LL, Goldberg SB, Breidenbach WC, 1970. Human coccidiosis: a possible cause of malabsorption. $N$ Engl J Med 283: 1306-1313.

8. Jongwutiwes S, Sampatanukul P, Putaporntip C, 2002. Recurrent isosporiasis over a decade in an immunocompetent host successfully treated with pyrimethamine. Scand J Infect Dis 34: 859-862.

9. Tiangtip R, Jongwutiwes S, 2002. Molecular analysis of Cryptosporidium species isolated from HIV-infected patients in Thailand. Trop Med Int Health 7: 357-364.

10. Morgan U, Weber R, Xiao L, Sulaiman I, Thompson RC, Ndiritu W, Lal A, Moore A, Deplazes P, 2000. Molecular characterization of Cryptosporidium isolates obtained from human immunodeficiency virus-infected individuals living in Switzerland, Kenya, and the United States. J Clin Microbiol 38: 11801183.

11. Xiao L, Ryan UM, 2004. Cryptosporidiosis: an update in molecular epidemiology. Curr Opin Infect Dis 17: 483-490.

12. Jongwutiwes S, Tiangtip R, Yentakarm S, Chantachum N, 2002. Simple method for long- term copro-preservation of Cryptosporidium oocysts for morphometric and molecular analysis. Trop Med Int Health 7: 257-264.

13. Thompson JD, Gibson TJ, Plewniak F, Jeanmougin F, Higgins DG, 1997. The Clustal X windows interface: flexible strategies for multiple sequence alignment aided by quality analysis tools. Nucleic Acids Res 25: 4876-4882.

14. Siebert S, Backofen R, 2005. MARNA: multiple alignment and consensus structure prediction of RNAs based on sequence structure comparisons. Bioinformatics 21: 3352-3359.

15. Kumar S, Tamura K, Nei M, 2004. MEGA3: Integrated software for Molecular Evolutionary Genetics Analysis and sequence alignment. Brief Bioinform 5: 150-163.

16. Franzen C, Muller A, Bialek R, Diehl V, Salzberger B, Fatkenheuer G, 2000. Taxonomic position of the intestinal protozoan parasite Isospora belli as based on ribosomal RNA sequences. Parasitol Res 86: 669-676.

17. Bialek R, Binder N, Dietz K, Knobloch J, Zelck UE, 2002. Comparison of autofluorescence and iodine staining for detection of Isospora belli in feces. Am J Trop Med Hyg 67: 304-305.

18. Mahrt JL, 1968. Sporogony of Isospora rivolta oocysts from the dog. J Protozool 15: 308-312.

19. Lepp D, Todd KS, 1976. Sporogony of the oocysts of Isospora canis. Trans Am Microsc Soc 95: 89-103.

20. Linsay DS, Current WL, Ernst JV, 1982. Sporogony of Isospora suis Biester, 1934 of swine. J Parasitol 68: 861-865.

21. Matsui T, Ito S, Fujino T, Morii T, 1993. Infectivity and sporogony of Caryospora-type oocyst of Isospora rivolta obtained by heating. Parasitol Res 79: 599-602.

22. Ferrer C, Colom F, Frasés S, Mulet E, Abad JL, Alió JL, 2001. Detection and identification of fungal pathogens by PCR and by ITS2 and 5.8S ribosomal DNA typing in ocular infections. $J$ Clin Microbiol 39: 2873-2879.

23. Young I, Coleman AW, 2004. The advantages of the ITS2 region of the nuclear rDNA cistron for analysis of phylogenetic relationships of insects: a Drosophila example. Mol Phylogenet Evol 30: 236-242.

24. Prakash A, Walton C, Bhattacharyya DR, Loughlin SO, Mohapatra PK, Mahanta J, 2006. Molecular characterization and species identification of the Anopheles dirus and An. minimus complexes in north-east India using r-DNA ITS-2. Acta Trop 100: $156-161$. 